University of Nebraska - Lincoln

DigitalCommons@University of Nebraska - Lincoln

Faculty Publications, Department of Psychology

Psychology, Department of

2005

\title{
Relationship Between Parent Satisfaction Regarding Partnerships With Professionals and Age of Child
}

\author{
Jean Ann Summers \\ University of Kansas, jsummers@ku.edu \\ Lesa Hoffman \\ University of Nebraska-Lincoln, Ihoffman2@unl.edu \\ Janet Marquis \\ University of Kansas, jmarquis@ku.edu \\ Ann Turnbull \\ University of Kansas, turnbull@ku.edu \\ Denise Poston \\ University of Kansas, denisep@ku.edu
}

Follow this and additional works at: https://digitalcommons.unl.edu/psychfacpub

Part of the Psychiatry and Psychology Commons

Summers, Jean Ann; Hoffman, Lesa; Marquis, Janet; Turnbull, Ann; and Poston, Denise, "Relationship Between Parent Satisfaction Regarding Partnerships With Professionals and Age of Child" (2005). Faculty Publications, Department of Psychology. 440.

https://digitalcommons.unl.edu/psychfacpub/440

This Article is brought to you for free and open access by the Psychology, Department of at DigitalCommons@University of Nebraska - Lincoln. It has been accepted for inclusion in Faculty Publications, Department of Psychology by an authorized administrator of DigitalCommons@University of Nebraska - Lincoln. 
Published in Topics in Early Childhood Special Education (2005) 25(1): 48-58. Copyright 2005, Pro-Ed/SAGE. Used by permission. http:/ / tec.sagepub.com/

\section{Relationship Between Parent Satisfaction Regarding Partnerships with Professionals and Age of Child}

\section{Jean Ann Summers*, University of Kansas}

Lesa Hoffman, University of Nebraska-Lincoln (formerly: Pennsylvania State University)

Janet Marquis, Ann Turnbull, Denise Poston, University of Kansas

*Beach Center on Disabilities, University of Kansas, Lawrence, KS, USA: jsummers@ku.edu

In the past, the assessment of families' satisfaction with the quality of their partnerships with the professionals who serve their children has been restricted to specific programs or age groups, precluding investigation of the relationship between parents' perspectives on satisfaction and the importance of partnership components for children at different ages. Differences in policies, service models, and family needs at different life-cycle stages suggest a need to understand how satisfaction might differ among parents of children of different ages. In this study, 147 parents completed the Beach Center Family-Professional Partnership Scale to describe the perceived importance of and satisfaction with 18 aspects of their child and family's relationships with their primary service provider. No differences in importance ratings among parents of children ages birth to 3 years, 3 to 5 years, and 6 to 12 years emerged, but there were differences among satisfaction ratings, with parents of older children reporting lower satisfaction. Exploratory analyses relating satisfaction levels across other demographic variables also took place. Implications of these findings for future research and application are discussed.

Parent satisfaction is frequently included as a component of evaluating services for children with disabilities and their families (e.g., Bailey, Scarborough, \& Hebbeler, 2003; Johnson \& Duffett, 2002). Measuring and assuring parent satisfaction is important for several reasons. First, the Individuals with Disabilities Education Act (IDEA) states that parents must be on decision-making teams in all special education services; parents have various due process mechanisms to pursue if they believe they are not receiving needed services for their children (Turnbull \& Turnbull, 2001). Therefore, assuring parent satisfaction will help prevent conflicts and their attendant legal mediation and due process hearings (Lake \& Billingsley, 2000).

Second, parent satisfaction may be related to other family outcomes, such as stress or depression (King, King, Rosenbaum, \& Goffin, 1999), increased empowerment (Thompson et al., 1997), or enhanced parent selfefficacy and involvement with the school (Laws \& Millward, 2001). Qualitative studies have suggested that parents who are dissatisfied with their relationships with professionals experience stress and feel unwelcome in decision-making and implementing inclusion strategies for their young children (e.g., Soodak \& Erwin, 2000). In the case of an African American parent, dissatisfaction may have led to withdrawal from early intervention (Rao, 2000). Conversely, other qualitative studies of families from diverse cultures have suggested that assuring parent satisfaction with services their children receive and with their relationships with professionals was critical to South Korean parents' involvement with their child's education (Park \& Turnbull, 2001).

\section{DEFINING SATISFACTION:}

FAMILY-PROFESSIONAL PARTNERSHIPS

Studies of parent satisfaction may ask parents to rate their satisfaction with (a) the amount of services they or their child received, (b) the quality of the services, and (c) the quality of their relationships with professionals (see, e.g., Bailey et al., 2003; Johnson \& Duffett, 2002; Laws \& Millward, 2001). On rare occasions, par- 
ents may also be asked to rate importance of aspects of services or their relationships with providers. One example of such an instrument is the Brass Tacks rating tool for families in early intervention (McWilliam, 1991). Rating the importance of components of services or of aspects of relationships helps families define the meaning of satisfaction that best fits their own culture and expectations. Furthermore, asking parents to rate the importance of aspects of satisfaction may reveal information about components of service or relationship quality that need to be maintained in measures of satisfaction.

McNaughton (1994) analyzed measures of parent satisfaction in early childhood programs and noted that most measures were highly specialized and targeted services to be evaluated for a given study. For example, Bailey and colleagues (2003) included a section assessing parent satisfaction in a broader longitudinal study of parents enrolled in early intervention programs. Similarly, McWilliam et al. (1995) developed a 30-item questionnaire specifically reflecting concerns of their state's Interagency Coordinating Council. Lanners and Mombaerts (2000) developed a measure of parent satisfaction with early intervention services in eight European countries. Each measure contains items specifically tailored to the purpose and nature of the evaluated services. Although there are common elements in many of these and other measures of parent satisfaction, the lack of common conceptualization and specificity of the tools militate against a thorough conceptualization of parent satisfaction across service settings, intervention models, and family characteristics. Making comparisons across reported investigations becomes difficult due to these flaws.

We propose a more inclusive definition of familyprofessional relationships implemented in the Beach Center Family-Professional Partnership Scale (Summers et al., in press). This scale is based on extensive qualitative study of family and provider perspectives on components in good partnerships and on subsequent field tests to develop and evaluate a measure reflecting these perspectives. Based on common elements of partnerships our qualitative study identified, we define family-professional partnerships as mutually supportive interactions between families and professionals, which focuses on meeting the needs of children and families with competence, commitment, equality, positive communication, respect, and trust (Blue-Banning, Summers, Frankland, Nelson, \& Beegle, 2004). Subsequent field tests to develop a measure reflecting these components of the partnership relationship revealed two primary factors: (a) the quality of the professional's care of the child (i.e., service satisfaction) and (b) the quality of the professional's relationships with the family (Summers et al., in press). These fac- tors are consistent with other measures targeting parent satisfaction with the quality of their child's services and of their relationship with service providers.

In summary, policy establishes pragmatic support for assessing and seeking parent satisfaction with services. Research results also suggest a link between parent satisfaction and positive outcomes for children and families. Thus, understanding the nature of parent satisfaction more fully, assessing satisfaction more reliably, and exploring implications of variations in satisfaction for policy and practice have become crucial. From a policy and research perspective, comparing parent satisfaction across service settings (e.g., home visiting programs vs. center-based), across different intervention models (e.g., family-centered programs vs. childcentered), or across various family characteristics (e.g., ethnic background) will be useful. The definition and measurement of partnerships that we have developed contain common elements across a wide range of families and service types and enable families to rate both the importance of and their satisfaction with common elements of partnership.

\section{IMPORTANCE OF UNDERSTANDING SATISFAC- TION ACROSS AGE GROUPS \\ Of particular interest is the possibility of comparing} the satisfaction of parents of children who are of different ages, given that a child's age is a marker for different service systems (e.g., Part $\mathrm{C}$ serves ages birth3; Part B serves older children) and that family needs and expectations may change with changing demands of the family life cycle. Such a comparison would also provide insight into the ways in which families' levels of satisfaction may be different for children of different ages, how different types of services might be perceived by families, and what elements of services are important to include for families of children of different age groups or other characteristics. Not surprisingly, given the specificity of most family satisfaction research, there is little insight about how family satisfaction might vary across the changing ages of children with disabilities. An exception is the study by McWilliam and colleagues (1995), which found that families receiving early intervention (ages birth-3) services were more satisfied with the help they received for family needs than were those receiving services for preschool-age children (3-5).

A study by Dunst (2002) reported a decline in family-centered practice in early intervention, preschool, elementary, and secondary special education programs. Dunst noted that family-allied program models, in contrast to those that are family-centered, are used more often in elementary and secondary education. Family-centered practice is related to but distinct from family-professional partnerships. As defined by 
several researchers, family-centered practice is a service model that supports the whole family as the unit of service and honors family choice and empowerment in decision-making about services (Allen \& Petr, 1996). The decline in use of family-centered practice at each service level may or may not be a problem, because we do not know parents' preferences for or satisfaction with their partnerships across all these levels. Do parents want professionals to maintain the same emphases in their relationships with their children as the children grow older? A similar question could be asked about the relationships with the family. Currently, we lack the research needed to answer these questions.

The purpose of this study is to begin addressing this unmet need by using the Beach Center Family- Professional Partnership Scale. Our central research questions are, Do parents' ratings of the importance of and their satisfaction with various aspects of professional partnerships differ with the age of the child with a disability? If so, what factors might contribute to the differences?

\section{METHOD}

\section{Participant Recruitment and Description}

Procedures used for recruiting the individuals who made up the sample for this study are described in greater detail elsewhere (Summers et al., in press; Turnbull et al., 2004). To summarize, participants were recruited through presentations at parent meetings or by collaboration with agencies wishing to conduct evaluations of their programs. For one agency, a local Head Start program, we collected data from 133 of the 180 families served; of these, 21 identified themselves as having a child with a disability and were included in this study. Three Kansas developmental disabilities agencies and one North Carolina agency invited families they worked with to attend evening meetings where light meals were served and where the research staff presented and collected the measures. In Michigan, Washington, and Louisiana, a parent organization offered the measures to families they worked with, either in group meetings or directly during individual consultations. These strategies helped recruit 147 respondents with children with disabilities, age 12 and under, from Kansas $(n=53)$, Michigan $(n=18)$, Washington State $(n=19)$, Louisiana $(n=20)$, and North Carolina $(n=37)$.

Respondents who were the subjects of analysis comprised 125 women (85\%) and 20 men (13.6\%; 2 missing responses), of whom 142 (97\%) were biological, foster, or adoptive parents, $4(3 \%)$ other relatives, and $1(1 \%)$ other nonrelatives. The majority of respondents were married $(105,71.4 \%), 16$ were divorced $(10.9 \%)$, 9 were separated $(6.1 \%)$, and 15 had never been married (15, $10.2 \%)$, with 2 missing responses (1.4\%). Respondent ages ranged from 19 to $60(M=36.2, S D=7.7)$, with the majority in their 30s. The majority of respondents were White non-Hispanic $(114,77.6 \%)$, with the rest of the participants being Hispanic $(6,4.1 \%)$, American Indian or Alaskan Native $(2,1.4 \%)$, Asian or Pacific Islander $(7,4.8 \%)$, Black $(13,8.8 \%)$, or of another group (Other, 5, 3.4\%). Educational attainment levels included 42 (28.6\%) people who had a high school diploma/GED or less, $49(33.3 \%)$ with some college or an associate's degree, $42(28.6 \%)$ with a bachelor's degree, and $14(9.5 \%)$ with a graduate degree. Concerning annual household income, 48 (32.7\%) reported an income of less than $\$ 27,000,40(27.2 \%)$ reported an income between $\$ 27,000$ and $\$ 55,000,53(36.1 \%)$ reported an income greater than $\$ 55,000$, and $6(4.1 \%)$ responses were missing. In response to questions about community size, $38(25.9 \%)$ of respondents reported living in a large city or metropolitan area (> 200,000), $26(17.7 \%)$ in an urbanized area (50,000-200,000), $64(44.5 \%)$ in a town or small city, $16(10.9 \%)$ in a rural area or town (< $2,500)$, and $3(2.0 \%)$ responses were missing.

Children of the respondents comprised 47 girls $(32 \%)$ and 100 boys (68\%) with disabilities, of which $48(32.7 \%)$ were between the ages of birth and 2 years, $44(29.9 \%)$ between 3 and 5 years, and $55(37.4 \%)$ between 6 and 12 years. Their reported disabilities included autism spectrum disorder; developmental delay; attention-deficit disorder or attention-decifit/ hyperactivity disorder; mental retardation; emotional, learning, and physical disabilities; speech/language; vision, hearing, and health impairments; traumatic brain injuries; and mental illness. Of these disabilities, $25(17.0 \%)$ were characterized by respondents as mild, $59(40.1 \%)$ as moderate, $34(23.1 \%)$ as severe, $12(8.2 \%)$ as very severe, and $15(10.2 \%)$ as unknown (2 missing responses, $1.4 \%)$.

\section{The Beach Center Family-Professional Partnership Scale}

Initial development of the Beach Center Family- Professional Partnership Scale was derived from results of a qualitative study involving focus groups and individual interviews with families with children with and without disabilities; direct care service providers from agencies in health, education, and social services; and administrators from those same agencies, as described in Blue-Banning et al. (2004). A set of 60 items was drawn up for the pilot version of the instrument to assess domains of communication, commitment, respect, trust, equality, and skills of service providers. The scale was refined across two independent field tests into 18 items that fall into two primary subscales: Child-Focused Relationships and FamilyFocused Relationships, as described in Summers et al. (in press). Items' importance ratings and satisfaction ratings are listed in Tables 1 and 2, respectively. 
TABLE 1. Descriptive Statistics for Importance Ratings by Item by Age Group

\begin{tabular}{|c|c|c|c|c|c|c|c|c|c|}
\hline \multirow[b]{2}{*}{ Item } & \multicolumn{3}{|c|}{ Birth-3 years } & \multicolumn{3}{|c|}{$3-5$ years } & \multicolumn{3}{|c|}{$6-12$ years } \\
\hline & $n$ & $M$ & $S D$ & $n$ & $M$ & $S D$ & $n$ & $M$ & $S D$ \\
\hline Child $M$ & 49 & 4.55 & 0.55 & 47 & 4.67 & 0.39 & 58 & 4.55 & 0.60 \\
\hline Item 1 & 50 & 4.34 & 1.02 & 47 & 4.57 & 0.71 & 57 & 4.26 & 0.92 \\
\hline Item 2 & 50 & 4.68 & 0.68 & 47 & 4.74 & 0.53 & 57 & 4.67 & 0.74 \\
\hline Item 3 & 49 & 4.59 & 0.70 & 45 & 4.78 & 0.47 & 58 & 4.67 & 0.73 \\
\hline Item 4 & 42 & 4.33 & 1.00 & 45 & 4.49 & 0.73 & 57 & 4.40 & 0.94 \\
\hline Item 5 & 49 & 4.35 & 0.90 & 47 & 4.49 & 0.75 & 56 & 4.41 & 0.85 \\
\hline Item 6 & 49 & 4.67 & 0.72 & 47 & 4.72 & 0.58 & 58 & 4.71 & 0.65 \\
\hline Item 7 & 50 & 4.54 & 0.71 & 46 & 4.67 & 0.60 & 57 & 4.47 & 0.83 \\
\hline Item 8 & 49 & 4.51 & 0.79 & 47 & 4.66 & 0.56 & 58 & 4.60 & 0.77 \\
\hline Item 9 & 48 & 4.85 & 0.46 & 47 & 4.91 & 0.35 & 55 & 4.82 & 0.64 \\
\hline Family $M$ & 51 & 4.29 & 0.69 & 46 & 4.39 & 0.55 & 56 & 4.32 & 0.65 \\
\hline Item 10 & 50 & 4.18 & 0.90 & 47 & 4.34 & 0.87 & 58 & 4.26 & 0.87 \\
\hline Item 11 & 47 & 4.53 & 0.75 & 47 & 4.53 & 0.78 & 57 & 4.49 & 0.80 \\
\hline Item 12 & 52 & 3.92 & 1.10 & 46 & 4.09 & 1.01 & 56 & 3.89 & 1.30 \\
\hline Item 13 & 51 & 4.33 & 0.84 & 45 & 4.40 & 0.81 & 56 & 4.38 & 0.95 \\
\hline Item 14 & 51 & 4.25 & 0.84 & 45 & 4.42 & 0.78 & 55 & 4.47 & 0.84 \\
\hline Item 15 & 51 & 4.31 & 0.81 & 45 & 4.44 & 0.78 & 56 & 4.32 & 0.86 \\
\hline Item 16 & 51 & 4.45 & 0.73 & 46 & 4.59 & 0.62 & 56 & 4.43 & 0.87 \\
\hline Item 17 & 51 & 4.45 & 0.90 & 46 & 4.52 & 0.69 & 56 & 4.46 & 0.83 \\
\hline Item 18 & 51 & 4.22 & 1.12 & 46 & 4.22 & 0.92 & 56 & 4.23 & 0.83 \\
\hline
\end{tabular}

TABLE 2. Descriptive Statistics for Satisfaction Ratings by ltem by Age Group

\begin{tabular}{|c|c|c|c|c|c|c|c|c|c|}
\hline \multirow[b]{2}{*}{ Item } & \multicolumn{3}{|c|}{ Birth-3 years } & \multicolumn{3}{|c|}{$3-5$ years } & \multicolumn{3}{|c|}{$6-12$ years } \\
\hline & $n$ & $M$ & $S D$ & $n$ & $M$ & $S D$ & $n$ & $M$ & $S D$ \\
\hline Child $M$ & 47 & 4.41 & 0.58 & 45 & 3.96 & 0.78 & 57 & 3.69 & 1.02 \\
\hline Item 1 & 46 & 4.07 & 1.00 & 44 & 3.70 & 1.19 & 57 & 3.25 & 1.26 \\
\hline Item 2 & 47 & 4.38 & 0.80 & 44 & 3.95 & 0.96 & 56 & 3.55 & 1.19 \\
\hline Item 3 & 48 & 4.33 & 0.88 & 43 & 3.67 & 1.19 & 57 & 3.42 & 1.24 \\
\hline Item 4 & 42 & 4.24 & 0.93 & 41 & 3.51 & 1.16 & 54 & 3.52 & 1.28 \\
\hline Item 5 & 49 & 4.59 & 0.67 & 45 & 4.02 & 1.08 & 55 & 3.84 & 1.18 \\
\hline Item 6 & 49 & 4.67 & 0.52 & 45 & 4.33 & 0.74 & 57 & 3.98 & 1.23 \\
\hline Item 7 & 47 & 4.36 & 0.74 & 45 & 4.07 & 1.03 & 56 & 3.57 & 1.26 \\
\hline Item 8 & 49 & 4.37 & 0.91 & 46 & 3.83 & 1.22 & 57 & 3.89 & 1.29 \\
\hline Item 9 & 48 & 4.73 & 0.45 & 44 & 4.50 & 0.95 & 53 & 4.17 & 1.24 \\
\hline Family $M$ & 47 & 4.54 & 0.54 & 45 & 4.13 & 0.79 & 55 & 3.96 & 0.87 \\
\hline Item 10 & 47 & 4.32 & 0.93 & 45 & 4.00 & 1.04 & 57 & 3.81 & 1.14 \\
\hline Item 11 & 43 & 4.30 & 0.86 & 44 & 4.16 & 0.94 & 56 & 3.80 & 1.23 \\
\hline Item 12 & 48 & 4.69 & 0.51 & 45 & 4.27 & 0.96 & 54 & 4.22 & 0.88 \\
\hline Item 13 & 47 & 4.62 & 0.53 & 44 & 4.27 & 0.92 & 55 & 3.89 & 1.13 \\
\hline Item 14 & 48 & 4.60 & 0.61 & 44 & 4.14 & 1.03 & 54 & 4.00 & 1.13 \\
\hline Item 15 & 48 & 4.65 & 0.53 & 43 & 3.98 & 1.10 & 55 & 3.82 & 1.25 \\
\hline Item 16 & 51 & 4.43 & 0.94 & 45 & 4.20 & 0.99 & 55 & 3.91 & 1.14 \\
\hline Item 17 & 49 & 4.59 & 0.61 & 45 & 4.00 & 1.02 & 55 & 3.85 & 1.28 \\
\hline Item 18 & 50 & 4.72 & 0.50 & 45 & 4.24 & 0.93 & 55 & 4.31 & 0.81 \\
\hline
\end{tabular}


Psychometric analyses revealed the overall scale and subscales to have sufficient internal consistency (as indicated by Cronbach's alphas) and to be unidimensional (as indicated by confirmatory factor analyses) with regard to parents' responses about the importance of and their satisfaction with each item. Cronbach's alphas for importance ratings were reported as $0.93,0.90$, and 0.88 for the overall 18-item scale and the 9-item Child- and Family-Focused Relationship subscales, respectively. Cronbach's alphas for satisfaction ratings were $0.96,0.94$, and 0.92 , respectively. Confirmatory factor analyses revealed acceptable fit of a correlated two-factor structure for both importance and satisfaction ratings, with Comparative Fit Indices (CFI) $=0.91$ and 0.90 , and root mean square errors of approximation $($ RMSEA $)=0.06$ and 0.08 for importance and satisfaction, respectively (for more information, see Summers et al., in press).

Participants were asked to respond to questions for each item regarding their child's service provider, such as "How important is it that ..." and "How satisfied am I that ..." Responses are given on a 5-point scale for each question: importance $(1=$ a little important, $3=$ important, and $5=$ critically important) and satisfaction $(1=$ very dissatisfied, $3=$ neither, and $5=$ very satisfied). In addition to the Beach Center Family-Professional Partnership Scale, participants also completed the Family Quality of Life Scale (Park et al., 2003; Turnbull et al., 2004) and a brief demographic questionnaire.

\section{RESULTS}

For both importance and satisfaction ratings, the authors calculated means for each subscale by averaging responses to the items in that subscale. Respondents were included in analyses only if at least seven items were answered within each subscale; therefore, sample sizes may vary due to incomplete data. Independent analyses of variance were used for each reported analysis. Results for importance and satisfaction ratings are presented separately below. An alpha level of 0.01 was used for all analyses to minimize experiment-wise error rates. In addition to $p$ values (which represent the probability of obtaining the observed mean sample difference if there are in fact no differences between groups in the population), eta-squared estimates of effect size are also provided. Eta-squared represents the proportion of total variance explained by the effect of interest, where larger values indicate bigger effects. The eta-squared statistic ranges from 0 to 1 , where 0.0099 is considered small, 0.0588 is considered medium, and 0.1379 is considered large (Cohen, 1988).

\section{Importance Ratings Across Age Groups}

Table 1 provides descriptive statistics across the age groups of birth to 3 years, 3 to 5 years, and 6 to 12 years for the importance ratings per item. The overall mean importance rating across all 18 items of the Beach Center Family-Professional Partnership Scale was 4.49 (SD = 0.53), and the 18 items had a Cronbach's alpha of .93. The mean importance ratings for the Child-Focused Relationships and Family-Focused Relationships subscales were $4.61(S D=0.53)$ and $4.38(S D=0.60)$, with Cronbach's alphas for the 9-item subscales of 0.90 and 0.88 , respectively. We then examined mean differences in the importance ratings across age groups. There were no significant differences in importance ratings across age groups for any subscale or item. Accordingly, the obtained effect sizes were all quite small, accounting for between $0.1 \%$ and $1.8 \%$ of variance in importance.

\section{Satisfaction Ratings Across Groups}

Table 2 provides descriptive statistics across the age groups of birth to 3 years, 3 to 5 years, and 6 to 12 years for satisfaction ratings per item. The overall mean satisfaction rating across all 18 items of the Beach Center Family-Professional Partnership Scale was 4.10 (SD = 0.81 ), and the 18 items had a Cronbach's alpha of 0.93 . The mean satisfaction ratings for the Child-Focused Relationships and Family-Focused Relationships subscales were $4.00(S D=0.89)$ and $4.19(S D=0.80)$, with Cronbach's alphas for the 9-item subscales of 0.94 and 0.93 , respectively.

We then examined mean differences in satisfaction ratings across age groups. Significant differences among age groups were obtained for the overall subscale means; therefore, we examined mean differences among age groups for each of the 18 items. As seen in Tables 3 and $4, p$ values from the overall analysis indicated significant differences across age groups for many items and for each subscale. Table 2 shows that parents of children ages 6 to 12 appear uniformly less satisfied than do parents of children ages 3 to 5, who also appear less satisfied than do parents of children birth to 3 years. Next, we conducted pairwise followups for significant items to examine differences among each age group separately using Tukey's honestly significant difference. Significant differences are noted in Tables 3 and 4.

For child-focused relationships, parents of children ages 6 to 12 were significantly less satisfied $(p<0.01)$ than were parents of children ages 3 to 5 for the overall sub-scale mean, as well as for 7 of the 9 items (Items 8, Value your opinion about your child's needs, and 9, Keep your child safe when your child is in their care, were not significantly different). Additionally, parents of children ages 3 to 5 were significantly less satisfied than parents of children ages birth to 3 years for the overall subscale mean and for Items 3 (Provides services that meet the individual needs of your child), 4 (Speak up for your child's best interests when working with other service providers), and 5 (Let you know about the good things your child does). 
TABLE 3. Child-Professional Relationship Items and Age Group Comparisons for Satisfaction Ratings

\begin{tabular}{|c|c|c|c|c|}
\hline Your child's service providers ... & $\begin{array}{l}\text { Overall } \\
p \text { value }\end{array}$ & $\begin{array}{c}\text { Overall } \\
\eta^{2}\end{array}$ & $\begin{array}{c}\text { Birth-3 } \\
\text { vs. } 6-12\end{array}$ & $\begin{array}{l}\text { Birth-3 } \\
\text { vs. } 3-5\end{array}$ \\
\hline Child-Professional Relationships subscale $M$ & $<.001^{*}$ & .118 & $*$ & $\because$ \\
\hline 1. Help you gain skills or information to get what your child needs & $.003^{*}$ & .083 & $*$ & \\
\hline 2. Have the skills to help your child succeed & $<.001 \%$ & .110 & $*$ & \\
\hline 3. Provide services that meet the individual needs of your child & $<.001^{*}$ & .107 & $*$ & $*$ \\
\hline 4. Speak up for your child's best interests when working with other service providers & $.007 *$ & .074 & $*$ & $*$ \\
\hline 5. Let you know about the good things your child does & $<.001 \%$ & .098 & $\because$ & $*$ \\
\hline 6. Treat your child with dignity & $<.001 \%$ & .095 & $*$ & \\
\hline 7. Build on your child's strengths & $<.001^{*}$ & .108 & $*$ & \\
\hline 8. Value your opinion about your child's needs & .029 & .050 & & \\
\hline 9. Keep your child safe when your child is in their care & .020 & .057 & & \\
\hline
\end{tabular}

*Significant difference at $p<.01$.

TABLE 4. Family-Professional Relationship Items and Age Group Comparisons for Satisfaction Ratings

\begin{tabular}{|c|c|c|c|c|}
\hline Your child's service providers ... & $\begin{array}{l}\text { Overall } \\
p \text { value }\end{array}$ & $\begin{array}{c}\text { Overall } \\
\eta^{2}\end{array}$ & $\begin{array}{c}\text { Birth-3 } \\
\text { vs. } 6-12\end{array}$ & $\begin{array}{l}\text { Birth-3 } \\
\text { vs. 3-5 }\end{array}$ \\
\hline Family-Focused Relationships subscale $M$ & $<.001 *$ & .097 & $*$ & $*$ \\
\hline 10. Are available when you need them & .058 & .041 & & \\
\hline 11. Are honest, even when they have bad news & .036 & .049 & & \\
\hline 12. Use words that you understand & .012 & .063 & & \\
\hline 13. Protect your family's privacy & $<.001 \%$ & .097 & $*$ & \\
\hline 14. Show respect for your family's values and beliefs & $.006^{*}$ & .072 & $*$ & \\
\hline 15. Listen without judging your child or family & $<.001 \%$ & .113 & $*$ & $*$ \\
\hline 16. Are people that I can depend on and trust & .038 & .046 & & \\
\hline 17. Pay attention to what you have to say & $.002 *$ & .088 & $*$ & $\because$ \\
\hline 18. Are friendly & $.006^{*}$ & .070 & $\because$ & $\because$ \\
\hline
\end{tabular}

* Significant difference at $p<.01$.

For family-focused relationships, parents of children ages 6 to 12 were significantly less satisfied than were parents of children ages 3 to 5 for the overall sub-scale mean, as well as for 5 of the 9 items (Items 10, Are available when you need them, 11, Are honest, even when they have bad news, 12, Use words that you understand, 16 Are people that I can depend on and trust, were not significantly different). Additionally, parents of children ages 3 to 5 were significantly less satisfied than were parents of children ages birth to 3 years for the overall subscale mean and for Items 12 (Use words that you understand), 15 (Listen without judging your child or family), 17 (Pay attention to what you have to say), and 18 (Are friendly).
Interaction of Age Group Differences With Other Family Demographic Characteristics

Although our main interest was examining mean differences in importance of and satisfaction with aspects of family-professional partnerships across age groups of the child with a disability, we also conducted exploratory analyses to examine the potential contribution of other demographic variables to the observed age differences in importance and satisfaction ratings. Sample sizes for some of these demographic groups were too small to carry out a multi-way factorial analysis of variance to determine relative contributions of various family characteristics. Therefore, we confined our analysis to separate, two-way independent analyses of variance. 
The characteristics examined were ethnic background (White vs. non-White), marital status (married vs. not married), educational background (high school or less vs. college), annual income level $(<\$ 26,999$, vs. $\$ 27,000$ $\$ 54,999$, vs. $>\$ 55,000)$, and community size $(>200,000$, $50,000-200,000,2,500-50,000$, or $<2,500$ persons in the community). The subscale means served as dependent variables. Each analysis also included the main effect of age group and its two-way interaction with the demographic variable. There were no significant main effects or interactions with age group of any of the demographic variables for importance ratings, so further descriptive information is not provided. For satisfaction, however, there was a suggestion of possible differences across demographic variables, as described below.

Tables 5 and 6 display the means by age group for each level of demographic variables for each subscale for satisfaction ratings. For ethnic background, although there were no main effects, there were marginal and significant interactions with age group for child-professional relationships $\left(p=0.046, \eta^{2}=0.047\right)$ and family-professional relationships $\left(p=0.002, \eta^{2}=0.097\right)$, respectively. For both variables, the pattern of interaction was such that White respondents indicated lower satisfaction with the increasing ages of their children, whereas non-White respondents indicated lowest satisfaction if their children were between 3 to 5 years, followed by 6 to 12 years. However, given the small number of respondents in the latter two categories (7 and 5, respectively), these results must be viewed as exploratory. For marital status, although there were no main effects, there were marginal interactions with age group for both child-professional relationships $(p$ $\left.=0.060, \eta^{2}=0.042\right)$ and family-professional relationships $\left(p=0.060, \eta^{2}=0.042\right)$. For both variables, the pattern of interaction was such that although both groups reported lower satisfaction with increasing age, nonmarried respondents showed greater variability in their satisfaction responses across age groups. Again, discrepancy in sample sizes between married and nonmarried respondents indicates a need for caution in interpreting these results.

For educational background, there was a marginal main effect for child-professional relationships $(p=$ $\left.0.044, \eta^{2}=0.030\right)$, such that college-educated respondents appeared somewhat less satisfied; no interaction with age group was obtained. Similar trends for family- professional relationships emerged, but no effects approached significance. Although there were no main effects for annual income level, there was a significant interaction with age group for child-professional relationships $\left(p=0.001, \eta^{2}=0.141\right)$ and a marginal interaction with age group for family-professional relationships $\left(p=0.054, \eta^{2}=0.071\right)$. For both variables, the pattern of interaction was such that respondents with lower $(<\$ 26,000)$ or higher $(>\$ 55,000)$ incomes expressed lower satisfaction with increasing age, whereas middle-income respondents were least satisfied if their children with disabilities were between ages 3 and 5 . There were no main effects of community size or interactions with age group. Finally, significant negative correlations were found between respondent age and child-professional relationships satisfaction $(r=-0.26, p<0.001)$ and family-professional relationships satisfaction $(r=-0.21, p=0.006)$, indicating that older respondents were generally less satisfied than were younger respondents.

\section{DISCUSSION}

\section{Summary of Results and Limitations}

The primary purpose of the study was to compare parents of children with disabilities of varying ages (who are served by different types of agencies) in their reported levels of satisfaction with, and the importance of, aspects of family-professional partnerships. A secondary purpose was investigating whether other family demographic characteristics interact with child age in predicting observed differences in levels of importance and satisfaction. A total of 147 respondents completed the 18-item Beach Center Family-Professional Partnerships Scale, which is composed of two subscales relating to Child-Focused Relationships and Family-Focused Relationships. With respect to importance ratings, no differences across age groups of the children with disabilities were found, suggesting that parents in our sample did not differ in their perceptions of importance of these relationships. The finding that age differences accounted for less than $2 \%$ of variance in importance ratings suggests that this null result (i.e., no differences across age groups) is likely not due to low statistical power. Nearly all the obtained were above 4 on the 5-point scale (where 3 indicates important and 5 indicates critically important), indicating that parents perceived all rated aspects of their professional partnerships as relatively important.

For satisfaction, however, significant differences were found for both subscales and for most items. Overall, parents of children ages 6 to 12 years in special education in elementary school programs were least satisfied, parents of children age birth to 3 years receiving infant and toddler early intervention services were most satisfied, with responses from parents of children ages 3 to 5 years receiving early childhood special education services falling somewhere in between. Nevertheless, the means for satisfaction (as seen in Table 5) were all above 3 on the 5 -point scale (where 3 indicates neither dissatisfied nor satisfied and 5 indicates very satisfied). The standard deviations (also seen in Table 2) were substantially larger than those for importance ratings, suggesting relatively greater variability in par- 
TABLE 5. Descriptive Statistics for Child-Professional Relationship Satisfaction Ratings by Age Group and Demographic Variable

\begin{tabular}{|c|c|c|c|c|c|c|c|c|c|}
\hline \multirow[b]{2}{*}{ Variable } & \multicolumn{3}{|c|}{ Birth- 3 years } & \multicolumn{3}{|c|}{$3-5$ years } & \multicolumn{3}{|c|}{$6-12$ years } \\
\hline & $n$ & $M$ & $S D$ & $n$ & $M$ & $S D$ & $n$ & $M$ & $S D$ \\
\hline \multicolumn{10}{|l|}{ Ethnic background } \\
\hline White & 31 & 4.33 & .49 & 34 & 4.08 & .70 & 47 & 3.60 & 1.06 \\
\hline Non-White & 12 & 4.52 & .82 & 6 & 3.34 & .82 & 5 & 4.14 & .94 \\
\hline \multicolumn{10}{|l|}{ Marital status } \\
\hline Married & 34 & 4.43 & .56 & 27 & 4.11 & .81 & 39 & 4.04 & .85 \\
\hline Not married & 11 & 4.84 & .37 & 14 & 4.19 & .82 & 12 & 3.60 & .99 \\
\hline \multicolumn{10}{|l|}{ Educational background } \\
\hline High school or less & 13 & 4.56 & .51 & 17 & 4.37 & .76 & 10 & 3.79 & 1.24 \\
\hline College-educated & 31 & 4.33 & .62 & 25 & 3.77 & .69 & 44 & 3.64 & 1.00 \\
\hline \multicolumn{10}{|l|}{ Annual income } \\
\hline$<\$ 26,999$ & 13 & 4.85 & .27 & 17 & 4.46 & .67 & 15 & 3.26 & 1.24 \\
\hline$\$ 27,000-\$ 54,999$ & 13 & 4.31 & .52 & 12 & 3.56 & .72 & 15 & 4.07 & .88 \\
\hline$>\$ 55,000$ & 16 & 4.09 & .65 & 12 & 3.75 & .59 & 22 & 3.63 & .97 \\
\hline
\end{tabular}

TABLE 6. Descriptive Statistics for Family-Professional Relationship Satisfaction Ratings by Age Group and Demographic Variable

\begin{tabular}{|c|c|c|c|c|c|c|c|c|c|}
\hline \multirow[b]{2}{*}{ Variable } & \multicolumn{3}{|c|}{ Birth-3 years } & \multicolumn{3}{|c|}{$3-5$ years } & \multicolumn{3}{|c|}{ 6-12 years } \\
\hline & $\bar{n}$ & $M$ & $\overline{S D}$ & $n$ & $M$ & $S D$ & $n$ & $M$ & $S D$ \\
\hline \multicolumn{10}{|l|}{ Ethnic background } \\
\hline White & 32 & 4.45 & .53 & 34 & 4.26 & .70 & 46 & 3.83 & .89 \\
\hline Non-White & 12 & 4.69 & .57 & 6 & 3.32 & .93 & 4 & 4.64 & .42 \\
\hline \multicolumn{10}{|l|}{ Marital status } \\
\hline Married & 34 & 4.43 & .56 & 27 & 4.11 & .81 & 39 & 4.04 & .85 \\
\hline Not married & 11 & 4.84 & .37 & 14 & 4.19 & .82 & 12 & 3.60 & .99 \\
\hline \multicolumn{10}{|l|}{ Educational background } \\
\hline High school or less & 13 & 4.66 & .51 & 17 & 4.43 & .75 & 10 & 3.99 & 1.06 \\
\hline College-educated & 32 & 4.48 & .56 & 25 & 3.97 & .79 & 42 & 3.92 & .85 \\
\hline \multicolumn{10}{|l|}{ Annual income } \\
\hline$<\$ 26,999$ & 13 & 4.88 & .28 & 17 & 4.41 & .72 & 15 & 3.67 & .93 \\
\hline$\$ 27,000-\$ 54,999$ & 13 & 4.30 & .58 & 12 & 3.79 & .83 & 15 & 4.10 & .91 \\
\hline$>\$ 55,000$ & 17 & 4.41 & .57 & 12 & 4.09 & .80 & 20 & 3.93 & .84 \\
\hline
\end{tabular}

ents' levels of satisfaction. The relatively high satisfaction ratings are consistent with other satisfaction studies, which have found that families of young children tend to give fairly high satisfaction ratings (see, e.g., Bailey et al., 2003; McWilliam et al., 1995). Although the meaning of observed differences in these relatively high satisfaction ratings is a matter of judgment, the finding that there were any variances among a population that in general is highly satisfied shows that these results are worthy of further exploration.

The size of age effects ranged from $5 \%$ to $11 \%$ of the variance accounted for in satisfaction levels, so consideration of additional factors may be necessary to further explain variation in satisfaction levels among parents. 
Accordingly, the current study also explored possible differences in satisfaction levels across other demographic variables and found several notable interactions with age group in satisfaction levels. Non-White respondents and middle-income respondents both expressed lower levels of satisfaction with professional partnerships for children ages 3 to 5 years than for ages 6 to 12 or birth to 3 years, as opposed to White respondents or respondents with relatively lower or higher income, who expressed lowest satisfaction for children ages 6 to 12. Additionally, although the pattern of lower satisfaction with increasing age was obtained for both married and non-married respondents, nonmarried respondents appeared more variable in their satisfaction levels than did married respondents. Finally, respondents who were relatively older and more educated appeared less satisfied than did younger respondents or respondents with less education.

Regarding limitations of the study, its nonrandom sample selection is a factor to be considered when interpreting results. Parents who completed the scale with other parents at group meetings were perhaps more highly involved in their child's education than a randomly sampled population, which may explain the relatively high satisfaction scores. Although efforts to recruit a sample from communities with diverse income and ethnic backgrounds were made, some demographic groups may not have been represented as well as other groups were because fewer minorities and respondents with low levels of formal education tend to volunteer for or complete paper-and-pencil surveys (Dillman, 2000). The small sample sizes in some groups and the post hoc nature of these findings suggest caution in interpreting possible reasons for these differences. Given that the current study was not designed to address these demographic variables specifically, additional work should be conducted to assess the extent to which these effects will be replicated in future samples.

\section{Implications for Future Research}

No reliable differences in importance levels across examined respondent demographic variables were found nor were there significant differences across age groups for perceived importance ratings. These results suggest that obtained differences in satisfaction do not stem from differing perceptions about what is important in successful family-professional partnerships. Items on the Beach Center Family-Professional Partnership Scale represent several fundamental aspects of human interaction (e.g., showing respect, paying attention, being available, protecting privacy). Thus, the Family-Professional Partnerships Scale is a promising instrument for comparing levels of satisfaction with professional partnerships across types of settings, ser- vices, or family characteristics, given that the aspects of service delivery the instrument addresses appear uniformly important to service recipients. Future research designed to compare other family characteristics (e.g., ethnicity) more rigorously, as well as to replicate the age group comparisons, is needed to understand whether items in this scale are considered highly important by most families. If these items reflect a consensus about what is important in family-professional partnerships, they will also have implications for policy and practice, to enhance training and services that support positive interactions with children and families. Although we found no studies making direct comparisons among age groups in our literature review, these findings are consistent with the literature as a whole, in which studies assessing families of younger children tend to report higher satisfaction ratings than do studies assessing families of older children. These studies, however, used different measures and different approaches to data collection. The availability of a measure that is compatible across age groups and settings provides an opportunity to better explore the meaning of these age differences in satisfaction. Assuming these observed differences in age groups are maintained in future studies, further research should focus on explaining these findings. The three age groups (birth-3, 3-5, and 6-12) represent distinct groups in terms of policies and service systems. Early intervention (birth-3) concentrates on family-centered services and is provided in a home-visiting service model in many communities. By contrast, early childhood special education services for preschool children ages 3 to 5 may be provided through home visiting or center-based services or by a combination of these services. Although the focus on family support is perhaps reduced in the Part B ages 3 to 5 preschool services, the focus remains a familycentered as well as a non-categorical, developmental approach to services. In contrast, children experiencing the transition to special education programs at age 6 are introduced (along with their parents) to categorical services, inclusion in general education classrooms (or not), and a much-reduced emphasis on family support. That the service system reflects reduced emphasis on a family-centered philosophy as children grow older (Dunst, 2002) does not explain these findings, however. Conceptually, the Family-Professional Partnership Scale is similar but not analogous to family-centeredness. In fact, the child-orientation subscale focuses on aspects of the professional's relationship with the child and shows a pattern of age-group related satisfaction differences similar to those of the overall scale and the family-orientation sub-scale.

An alternative explanation is that parents may be increasingly sophisticated about their rights and expectations as their child grows up. Evidence for this 
possibility may lie in our finding that parents with college educations were less satisfied than those with high school education or less. The number of families at different educational levels was too small to enable more extensive analyses to determine whether there is a consistent inverse relationship between education and satisfaction. However, these results suggest a need for further research to explore this question. We also observed an inverse relationship between parent age and levels of satisfaction. If this relationship is observed in further research, that would lead to an alternative explanation, besides differing service systems, that the age of the child may be a marker for parents' familiarity with the service system and that greater knowledge about programs may be associated with lower satisfaction. Such an interpretation would be consistent with Bailey, Skinner, Rodriguez, Gut, and Correa (1999), who found in their study of Latino families that greater awareness of services was related to lower satisfaction among these families. However, the National Early Intervention Longitudinal Study (Bailey et al., 2003) found that more highly educated and higherincome families tend to have lower satisfaction with the amount of their services, whereas ethnic minorities and lower-income families tended to have lower satisfaction with the quality of their services, as well as the quality of their interactions with professionals. Interaction of satisfaction with family characteristics is quite complex and requires more research with larger samples across different types of services and family characteristics. Exploring these questions requires creative research designs, perhaps incorporating both quantitative components - such as using standard measures enabling comparisons across populations and service settings - and qualitative approaches to explore attitudes and contexts of parent satisfaction and the meaning behind observed differences.

These findings about service satisfaction should also be considered in the context of research on the impact of children with disabilities on families. For example, a longitudinal study of 183 children with Down syndrome and their families found that both mothers and fathers showed patterns of increasing stress from the time their children entered early intervention until their children reached age 10 (Hauser-Cram, Warfield, Shonkoff, \& Krauss, 2001). In another study of parents of children with autism, age of children and severity of disabilities contributed to depression for mothers but not for fathers (Gavin, 2001). If future research confirms that parents show declining satisfaction with services as their children grow up, as this study suggests in a cross-section, then this finding needs investigation in respect to general increases in parental stress over time. Do parents express greater dissatisfaction with services because they are experiencing greater stress with their child or vice versa: Do increasingly unsatisfactory services contribute to greater parental stress? Whatever the response, service programs should consider how best to address the apparent need for improved parental supports as children mature.

Even if results of our research are substantiated in future studies, early intervention providers must not rest on their laurels. We do not know what aspects of service models or program policies contribute to the findings, so we cannot conclude that early intervention in general has no need for improvement in familyprofessional relationships. As noted earlier, one explanation for higher satisfaction ratings at younger ages may be that parents do not yet know what to expect or do not understand their rights to various services and supports. Consequently, our findings suggest that early intervention programs need accountability checks from other sources besides parents, who tend to be unfamiliar with requesting supports and services.

\section{CONCLUSION}

The problem of evaluating parent satisfaction with intervention models, such as the family-centered practice model, requires separation of contributions to parent satisfaction levels based on continuing experience with service programs in general as their child matures, from the actual contribution of the model itself. This task is challenging because the nature of the service model tends to change as children mature. Determination of whether specific intervention models (e.g., family-centered practice) or settings (e.g., home-based vs. center-based) are primary sources of different levels of satisfaction requires a standardized, easily-administered measure that is applicable across a wide range of settings, age groups, and family characteristics, such as was administered in the current study.

The importance of developing strong partnerships with families is well established. Ability to determine what service models and settings are conducive to higher parent satisfaction with partnerships is a key to improving those partnerships. Incorporation of reliable measures for judging the quality of those partnerships, based on family satisfaction, will help researchers, practitioners, and policy makers create programs that are fully responsive to family needs and preferences.

\section{REFERENCES}

Allen, R. I., \& Petr, C. G. (1996). Toward developing standards and measurements for family-centered practice in family support programs. In G. H. S. Singer, L. E. Powers, \& A. L. Olson (Eds.), Redefining Family Support: Innovations in Public-Private Partnerships (pp. 57-86). Baltimore: Brookes.

Bailey, D. B., Skinner, D., Rodriguez, P., Gut, D., \& Correa, V. (1999). Awareness, use, and satisfaction with services for Latino parents of young children with disabilities. Exceptional Children, 65, 367-381. 
Bailey, D., Scarborough, A., \& Hebbeler, K. (2003). Families' First Experiences with Early Intervention. Menlo Park, CA: SRI International.

Blue-Banning, M., Summers, J. A., Frankland, C., Nelson, L. G., \& Beegle, G. (2004). Dimensions of family and professional partnerships: Constructive guidelines for collaboration. Exceptional Children, 70(2), 167-184.

Dillman, D.A. (2000). Mail and Internet Surveys: The Tailored Design Method. New York: Wiley.

Dunst, C. J. (2002). Family-centered practices: Birth through high school. Journal of Special Education, 36(3), 139-147.

Gavin, D. M. (2001). Parents of children with autism: Psychosocial functioning, social cognitions, and perceptions of services. Dissertation Abstracts International, Section B: The Sciences and Engineering, 61, 4446.

Hauser-Cram, P., Warfield, M. E., Shonkoff, J. P., \& Krauss, M. W. (2001). Children with disabilities: A longitudinal study of child development and parent well-being. Monographs of the Society for Research in Child Development, 66 (3, Serial No. 266).

Johnson, J., \& Duffett, A. (2002). When It's Your Own Child: A Report on Special Education from the Families Who Use It. New York: Public Agenda.

King, G., King, S., Rosenbaum, P., \& Goffin, R. (1999). Family-centered caregiving and well-being of parents of children with disabilities: Linking process with outcome. Journal of Pediatric Psychology, 24(1), 41-53.

Lake, J. F., \& Billingsley, B. S. (2000). An analysis of factors that contribute to parent-school conflict in special education. Remedial and Special Education, 21(4), 240-251.

Lanners, R., \& Mombaerts, D. (2000). Evaluation of parents' satisfaction with early intervention services within and among European countries: Construction and application of a new parent satisfaction scale. Infants $\mathcal{E}$ Young Children, 12(3), 61-70.

Laws, G., \& Millward, L. (2001). Predicting parents' satisfaction with the education of their child with Down's syndrome. Educational Research, 43(2), 209-226.

McNaughton, D. (1994). Measuring parent satisfaction with early childhood intervention programs: Current practice, problems, and future perspectives. Topics in Early Child- hood Special Education, 14(1), 26-48.

McWilliam, P. J. (1991). Brass Tacks: A Self-Rating of Family Centered Practices in Early Intervention. Chapel Hill, NC: Frank Porter Graham Child Development Center.

McWilliam, R. A., Lang, L., Vandiviere, P., Angell, R., Collins, L., \& Underdown, G. (1995). Satisfaction and struggles: Family perceptions of early intervention services. Journal of Early Intervention, 19(1) 43-60.

Park, J., Hoffman, L., Marquis, J., Turnbull, A. P., Poston, D., Mannan, H., et al. (2003). Toward assessing family outcomes of service delivery: Validation of a Family Quality of Life Survey. Journal of Intellectual Disability Research, 47(5), 367-384.

Park, J., \& Turnbull, A. P. (2001). Cross-cultural competency and special education: Perceptions and experiences of Korean parents of children with special needs. Education and Training in Mental Retardation and Developmental Disabilities, 36(2), 133-147.

Rao, S. S. (2000). Perspectives of an African American mother on parent-professional relationships in special education. Mental Retardation, 38(6), 475-488.

Soodak, L., \& Erwin, E. (2000). Valued member or tolerated participant: Parents' experiences in inclusive early childhood settings. Journal of the Association for Persons with Severe Handicaps, 25, 29-41.

Summers, J. A., Hoffman, L., Marquis, J., Turnbull, A. P., Poston, D., \& Nelson, L. L. (2005). Measuring the quality of family-professional partnerships in special education services. Exceptional Children, 72(1), 65-80.

Thompson, L., Lobb, C., Elling, R., Herman, S., Jurkiewicz, T., \& Hulleza, C. (1997). Pathways to family empowerment: Effects of family-centered delivery of early intervention services. Exceptional Children, 64(1), 99-113.

Turnbull, A. P., \& Turnbull, H. R. (2001). Families, Professionals, and Exceptionality: A Special Partnership. Columbus, $\mathrm{OH}$ : Merrill.

Turnbull, A. P., Marquis, J. G., Hoffman, L., Poston, D. J., Mannan, H., Wang, M., et al. (2004). A new tool for assessing family outcomes: Psychometric evaluation of the Family Quality of Life Scale. Manuscript submitted for publication. 